\title{
Application of PSA Kinetics on Prostate Cancer: Experience of Pharmacovigilance Department of University Hospital Establishment of ORAN (UHE) in Algeria
}

\author{
Chadou $\mathrm{H}^{1 *}$, Fetati $\mathrm{H}^{1}$, Boulerial $\mathbf{A}^{1}$, Keroumi ${ }^{2}$, Boudia $\mathrm{F}^{1}$, Belbouche \\ $\mathrm{N}^{1}$ and Toumi $\mathrm{H}^{1}$ \\ ${ }^{1}$ Pharmacovigilance department of UHEO / Research laboratory in pharmaceutical \\ development (RLPD), Algeria \\ ${ }^{2}$ Urology department of UHEO, Algeria
}

*Corresponding author: Hassane Chadou, Pharmacovigilance department of UHEO / Research laboratory in pharmaceutical development (RLPD), University of Oran - EHU Hospital, Algeria, Tel: +213779165285; Email: hassane15mobile@gmail.com

\section{Abstract}

Many international studies have shown the interest of prostate specific antigen (PSA) in prostate cancer monitoring, although it is not very specific to this pathology, it remains the best marker for the evaluation of prostate cancer, the effectiveness of anticancer therapy and the detection of recurrence. Interpretation of static serum levels of this marker is insufficient to assess the effectiveness of cancer treatment or predict the risk of relapse, hence the need to use other more appropriate methods based on the kinetics of tumor markers. The arrival in the laboratories of medical analysis of the kinetic software made it possible to facilitate the automatic tracing of the evolution curves of the tumor markers as a function of time and as well as the interpretation of the results obtained by the clinicians. The objective of this work is to analyze the biological data received from a population of patients with prostate cancer at the level of the pharmacovigilance service of the University Hospital Establishment 1 November 1954-ORAN (EHUO), and to study the kinetics of PSA serum using the software "CHA-TM KINETIC" (develop and coded by Dr. CHADOU Hassane).

Analysis of the results showed that the majority of patients had advanced cancer with high risk (70\%); which corresponds, according to Amico's classification, to a survival rate without recurrence for 10 years of $38.8 \%$.

Analysis of the kinetics of PSA indicates that $100 \%$ of patients presented NADIR $\leq 0.2 \mathrm{ng} / \mathrm{ml}$ for a long time, which corresponds to the absence of biological recurrence in our study population, and a very high half-life time (31.50 \pm 4.36$)$ days explained by non-compliance with the dosing schedule. 
The study of the kinetics of PSA using the CHA-TM KINETIC software in combination with other clinical and histopathological parameters in uro-oncology could improve the quality of monitoring of cancer patients providing it is properly used according to the calendars and dosing methods.

Keywords: PSA; Tumor markers; Kinetics CHA-TM KINETIC

\section{Introduction}

The prostate specific antigen (PSA) is today the best marker of prostate cancer, although it is not very specific to this pathology $[1,2]$. Numerous studies have clarified its clinical indications, its interest in the evaluation of therapeutic efficacy and in the detection of recurrences [3-7]. Indeed, the interpretation of the serum levels of this marker based on the notion of kinetics is more sensitive and relevant than that based on the notion of statistical threshold whose value is often adapted neither to the nature of the treatment instituted nor to the goal of signal precocity, or even the dosing reagents used [8-12]. In the kinetic approach, each patient is his own control and any new tumor marker concentration is interpreted according to the previous value. The arrival in medical analysis laboratories of kinetic software facilitated the automatic tracing of the evolution curves of tumor markers as a function of time and the interpretation of results obtained by clinicians [11-14]. The objective of this work is to analyze the biological data received from patients with prostate cancer at the level of the pharmacovigilance service of the University Hospital Establishment 1 November 1954 - ORAN (EHUO), and to study the kinetics of PSA serum using the software "CHA-TM KINETIC (develop and coded by Dr. CHADOU Hassane).

\section{Patients and Methods}

It is a prospective retrospective study covering a period of 6 years, from January 2011 to August 2017, which took place at the EHU pharmacovigilance service in Oran, France. Cancer patients warning of the EOHCU Urology Department. These patients were selected according to the following criteria:

\section{Inclusion Criterion}

$\checkmark$ Patients with prostate cancer.

$\checkmark$ Patients undergoing total prostatectomy.

$\checkmark$ Patients who have benefited from biological monitoring by PSA measurement.

\section{Exclusion criterion}

$\checkmark$ Patients receiving treatment by other means (radiotherapy, hormone therapy, chemotherapy) alone or in combination.

$\checkmark$ Patients for whom there is a lack of information. They were followed before and after total prostatectomy to evaluate the interest of the kinetic parameters of the tumor markers.

The collection of patient demographic and clinical information including the patient's first and last name, date of admission, treatment protocols, type of cancer, patient's clinical status, PSA's biological values, the TNM class of the patient. Cancer and the Gleason score was performed on a web page created by Dr. CHADOU Hassane. The treatment of the received data, as well as the plasma kinetics analysis of PSA: the plotting of the curves and the calculation of the kinetic parameters for each patient were carried out using the "CHA-TM KINETIC" software. The statistical analysis was performed by JASP software version 0.8.3.1.

\section{Results}

\section{Patient Demographic Characteristics}

Our study included 18 patients whose age ranged between 53 and 73 years with an average of (65.72 \pm 1.51) years (Table 1$)$.

\begin{tabular}{|c|c|}
\hline Age (Years) & Patient (\%) \\
\hline 53 & 5.56 \\
\hline 56 & 5.56 \\
\hline 59 & 11.11 \\
\hline 62 & 5.56 \\
\hline 63 & 11.11 \\
\hline 64 & 11.11 \\
\hline 65 & 5.56 \\
\hline 69 & 5.56 \\
\hline 71 & 5.56 \\
\hline 72 & 16.67 \\
\hline 73 & 16.67 \\
\hline
\end{tabular}

Table 1: Distribution of patients according to the age. 


\section{Cancer stage}

According to the AJCC [15] multicriteria staging, our population consisted of cancer patients with stages ranging from 1 to $4 \mathrm{~B}$ (Table 2 ).

\begin{tabular}{|c|c|c|c|c|c|}
\hline $\begin{array}{l}\text { Number of } \\
\text { patients }\end{array}$ & Stage & TNM & Gleason & PSA (ng/ml) & tumor Characteristics \\
\hline 1 & 1 & T1 ou T2a-N0-M0 & 6 or lower & $<10$ & $\begin{array}{c}\text { Located with PSA and Gleason } \\
\text { down }\end{array}$ \\
\hline 5 & $2 \mathrm{~A}$ & $\begin{array}{c}\text { T1-N0-M0 } \\
\text { T2a ou T2b-N0-M0 }\end{array}$ & $\begin{array}{c}6 \text { or }<6 \\
7 \\
7 \text { or }<7\end{array}$ & $\begin{array}{c}\text { Entre } 10 \text { et } 20 \\
\quad<20 \\
\quad<20\end{array}$ & $\begin{array}{c}\text { Localized with PSA or Gleason } \\
\text { high. }\end{array}$ \\
\hline 8 & 2B & $\begin{array}{c}\text { T2c-N0-M0 } \\
\text { T1 ou T2-N0-M0 }\end{array}$ & 8 or $>8$ & $>20$ & $\begin{array}{l}\text { Extended to } 2 \text { lobes but } \\
\text { localized. } \\
\text { Localized with Gleason or PSA } \\
\text { very high. }\end{array}$ \\
\hline 3 & 3 & T3-N0-M0 & & & $\begin{array}{l}\text { Extracapsular extension and / } \\
\text { or seminal vesicles. }\end{array}$ \\
\hline 0 & $4 \mathrm{~A}$ & T4-N0-M0 & & & extension to adjacent organs. \\
\hline 1 & 4B & $\begin{array}{l}\text { all T-N1-M0 } \\
\text { all T-tout N-M1 }\end{array}$ & & & $\begin{array}{l}\text { Extension to regional lymph } \\
\text { nodes or with distant } \\
\text { metastases. }\end{array}$ \\
\hline
\end{tabular}

Table 2: Distribution of patients according to the stage of cancer according to the American Joint Committee on Cancer (AJCC).

The 2B Stage was predominant (present 28\%), it is followed by patients with a stage $2 \mathrm{~A}(28 \%)$, the stage 3 $(17 \%)$ and other stages $(1.4 \mathrm{~A}, 4 \mathrm{~B})$ present $(11 \%)$ (Figure 1).

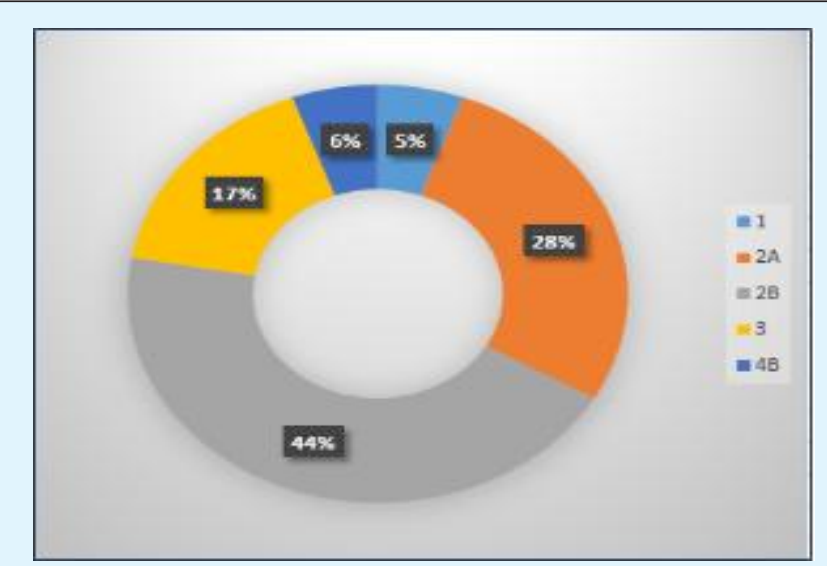

Figure 1: Distribution of patients by American Joint stage of cancer Committee on Cancer (AJCC).

\section{Severity of prostate cancer}

The distribution of patients according to d'Amico classification [15] showed that $72.22 \%$ of the study population was at high risk of cancer progression, patients with medium and low risk cancer represented less than $30 \%$ (Figure 2).

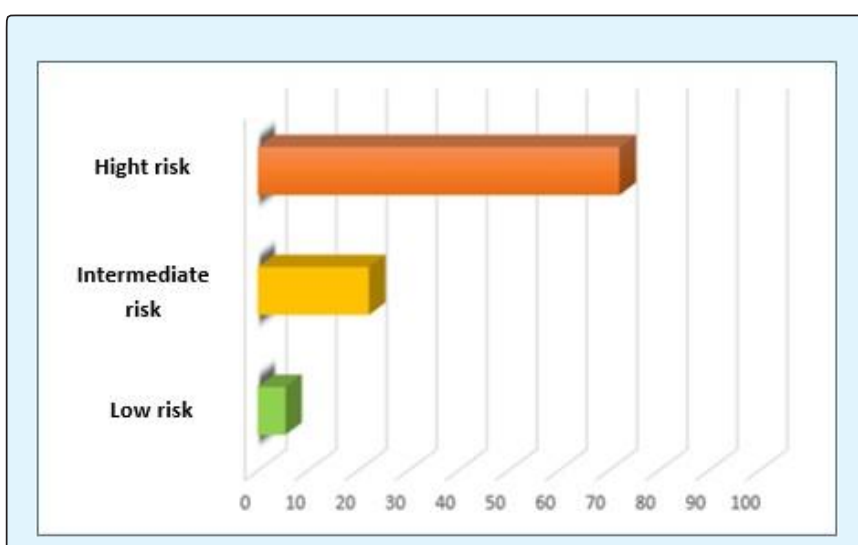

Figure 2: Distribution of patients according to the level of prostate cancer severity.

\section{Analysis of PSA Kinetic}

Determination of nadir: The results of the PSA nadirs after total prostatectomy obtained from the CHADOU-CMS system are represented in the following tables $3 \& 3 a$ : 


\begin{tabular}{|c|c|}
\hline Patient (s) & Nadir $\mathbf{( n g} / \mathbf{m l}$ ) \\
\hline 4 & 0,010 \\
\hline 1 & 0,0019 \\
\hline 3 & 0,0020 \\
\hline 1 & 0,0130 \\
\hline 2 & 0,0190 \\
\hline 1 & 0,0390 \\
\hline 2 & 0,0700 \\
\hline 1 & 0,0700 \\
\hline 1 & 0,1700 \\
\hline 1 & 0,4700 \\
\hline 1 & 0,6720 \\
\hline Total & 1.6599 \\
\hline Means $\pm \Delta \mathrm{S}$ & $0.0922 \pm 0.0430$ \\
\hline
\end{tabular}

Table 3: Distribution of patients according to NADIR values.

\begin{tabular}{|c|c|}
\hline Patient(s) & Half-life (jours) \\
\hline 1 & 39,05 \\
\hline 1 & 30,5 \\
\hline 1 & 44,49 \\
\hline 1 & 24,33 \\
\hline 1 & 83,52 \\
\hline 1 & 17,25 \\
\hline 1 & 5,83 \\
\hline 1 & 23,35 \\
\hline 1 & 23,44 \\
\hline 1 & 4,86 \\
\hline 1 & 43,97 \\
\hline 1 & 33,72 \\
\hline 1 & 27,31 \\
\hline 1 & 19,37 \\
\hline 1 & 16,17 \\
\hline 1 & 38,3 \\
\hline 1 & 53,12 \\
\hline 1 & 38,48 \\
\hline Total & 567.06 \\
\hline Means $\pm \Delta \mathrm{S}$ & $31.50 \pm 4.36$ \\
\hline
\end{tabular}

Table 3a: The nadir values ranged from $0.01 \mathrm{ng} / \mathrm{ml}$ to $0.672 \mathrm{ng} / \mathrm{ml}$ with an average value of $0.0922 \pm 0.0430 \mathrm{ng}$ / $\mathrm{ml}$.

Biologic recurrence: The biological recurrence after total prostatectomy is defined by the evolution of PSA concentrations (at least two points) above the Nadir limit value $=0.2 \mathrm{ng} / \mathrm{ml})[16,17]$.

The results are shown in the following table:

\begin{tabular}{|c|c|c|}
\hline Patient (s) & $\begin{array}{c}\text { No biological } \\
\text { recurrence(PSA } \\
<\mathbf{0 , 2} \mathbf{~ n g / m l )}\end{array}$ & $\begin{array}{c}\text { biological recurrence } \\
\text { (PSA } \mathbf{0 , 2} \text { ng/ml on two } \\
\text { successive points } \\
\text { at least) }\end{array}$ \\
\hline 18 & 18 & 0 \\
\hline
\end{tabular}

Table 4: Distribution of patients according to the presence or absence of biological recurrences.

Calculation of the half-life: The PSA half-lives of our study population ranged from 4.86 to 83.52 days with an average value of $(31.50 \pm 4.36)$ days (Table 5$)$.

\section{Discussion}

PSA is one of the most widely used biological markers in urology for the monitoring of prostate cancer. Although it presents a good sensitivity, it is not very specific of this pathology. In addition, the analysis of initial PSA values does not provide accurate information on the stage and course of cancer. It is therefore necessary to associate other parameters such as the Gleason score, the TNM stage according to the American Joint Committee on Cancer (AJCC) and Amico to better assess the risk.

Analysis of the PSA data, TNM classifications, and Gleason score [18] for each patient indicated that the majority of patients had advanced cancer with high risk (70\%); which corresponds, according to Amico's classification, to a 10-year recurrence-free survival rate of $38.8 \%$ [19]. Patients with low risk represented less than $10 \%$ of our study population corresponding to a $92 \%$ survival rate without recurrence according to the Amico classification. According to several studies, after a prostatectomy, there is a rapid drop in PSA levels. In the absence of secretory cells, the nadir values should be less than or equal to $0.2 \mathrm{ng} / \mathrm{ml}$. This was the case in our study population. Thus, all patients (100\%) had PSA concentrations $\leq 0.2 \mathrm{ng} / \mathrm{ml}$ for a long time. This showed the absence of changes in concentrations above the limit value, which corresponds to the absence of biological recurrence in our study population.

Regarding the half-life of PSA, the apparent clearance of PSA after prostatectomy is strongly influenced by the sampling chronology. The favorable half-life threshold is estimated between 2 and 3 days [6]. In our study, the mean value of half-lives found was very high (31.50 \pm 4.36) days despite the fact that the nadir values were less than $0.2 \mathrm{ng} / \mathrm{ml}$. This is explained by the non-compliance with the dosing schedule. .This study has certain limitations, namely the reduced sample size, the short duration of the study, and the non-compliance with the 
dosing schedule, which results in inaccurate results and limits the determination of other kinetic parameters such as time doubling.

\section{Conclusion}

PSA is one of the most used methods in urology for the monitoring of prostate cancer. Although it has a good sensitivity for this pathology, it is not very specific, and the use of static serum values does not make it possible to evaluate either the efficacy of the treatment or to predict the risk of recurrence.

The study of PSA kinetics using the CHA-TM KINETIC software in combination with other clinical and histopathological parameters makes it possible to determine the kinetic parameters linked to this tumor marker, which are powerful indicators of therapeutic efficacy and risk. relapses and also to have the recoil in order to be able to establish the threshold values of each kinetic parameter and to evaluate the real interest of these parameters in the follow-up of the anticancer therapeutic.

In addition, the use of the CHA-TM KINETIC software in uro-oncology is therefore necessary for the improvement of the quality of the follow-up of the cancer patients provided that it is used correctly noting by the respect of the schedules and the methods of dosages, thus the complete filling of the medical and clinical history of the patients.

\section{References}

1. Pinover WH, Horwitz EM, Hanlon AL, Uzzo RG, Hanks GE, et al. (2003) Validation of a treatment policy for patients with prostate specific antigen failure after three-dimensional conformal prostate radiation therapy. Cancer 97(4): 1127-1133.

2. Grima F, Rebillard X, Ruffion A (2005) Temps de doublement du PSA et son calcul. Progrès FMC 15(3): 17-19.

3. Crook JM, O'Callaghan CJ, Duncan G, Dearnaley DP, Higano CS, et al. (2012) Intermittent androgen suppression for rising PSA level after radiotherapy. N Engl J Med 367(10): 895-903.

4. Moul JW, Wu H, Sun L, McLeod DG, Amling C, et al. (2004) Early versus delayed hormonal therapy for prostate specific antigen only recurrence of prostate cancer after radical prostatectomy. J Urol 179(5): S53-59.

5. Ray ME, Thames HD, Levy LB, Horwitz EM, Kupelian PA, et al. (2006) PSA nadir predicts biochemical and distant failure after external beam radiotherapy for prostate cancer: a multi-institutional analysis. Int J Radiat Oncol Biol Phys 64(4): 1140-1150.

6. Riedinger JM, Eche N, Fulla Y, Thuillier F (2009) Cinétique du psa après prostatectomie totale. Ann Biol Clin 67(1): 39-46.

7. Stamey TA, Kabalin JN, McNeal JE, Johnstone IM, Freiha F, et al. (1989) Prostate specific antigen in the diagnosis and treatment of adenocarcinoma of the prostate. II. Radical prostatectomy treated patients. J Urol 141(5): 1076-1083.

8. Alexandre de la Taille, Alain Houlgatte, Patrice Houdelette, Patrick Berlizot, José Ramirez, et al. (1997) Intérêt du rapport PSA libre/PSA total dans le diagnostic précoce du cancer de la prostate (Etude de 105 patients). Progrès en Urologie 7: 240-245.

9. leban M, Thuillier F, Basuyau JP, Braidy C, Billion P, et al. (2008) L'avenir des marqueurs tumoraux : l'exploitation deleur cinétique. Étude CNBH 20042006, de larédaction d'un cahier des charges aux essais deslogiciels existants Kinetics of tumor markers : Good tools in the follow-up of cancers. A report of the $\mathrm{CNBH}$ tumor markers group. Immunoanalyse et biologie spécialisée 23(3): 119-129.

10. Riedinger JM, Nicole Eche (2005) Cinétique des marqueurs tumoraux au quotidien : mises en situation. Colloque DU SNBH 152: 42-47.

11. Vignot $S$, Brochet $C$, Debord C, Lauratet B, Bernard M (2011) Potential value of CA125 kinetic monitoring in the initial management of advanced epithelial ovarian cancer. Ann Biol Clin (Paris) 69(5): 597-604.

12. Mélanie Wilbaux (2014) Applications de la modélisation à l'analyse des cinétiques des marqueurs tumoraux sériques. HAL 1-220.

13. Georges A (2016) Marqueurs Biologiques Des Cancers Dépistage et Suivi. 1-38.

14. Lamy PJ, Grenier J (2004) Tomographie par émission de positons au 18Fluorodéoxyglucose et Marqueurs Tumoraux ; Laboratoire d'oncobiologie- Centre Régional de Lutte contre le Cancer Val d'Aurelle-Paul 
Lamarque. Imagerie fonctionnelle et métabolique 28(11): 1-7.

15. Salomon L (2013) score de gleason pour les nuls. Progrès en Urologie -FMC 24: F13-F15.

16. Boccon-Gibod L, Djavan WB, Hammerer P, Hoeltl W, Kattan MW, et al. (2004) Management of prostatespecific antigen relapse in prostate cancer: a European Consensus. Int J Clin Pract 58(4): 382-390.

17. Hutt E, Pasquier D (2015) Elévation secondaire du PSA après traitement initial.
18. Davin JL, Delmas V, Lebret T, Molinié V, Neuzill Y, et al. (2006) Cancer de la prostate à haut risque. Prog Urol 16: 661-670.

19. Rizk J, Ouzzane A, Flamand V, Fantoni JC, Puech P, et al. (2015) Survie sans récidive biologique à long terme après prostatectomie totale pour cancer : analyse comparative selon la voie d'abord et le stade clinico- pathologique. Prog Urol 25(3): 157-168.

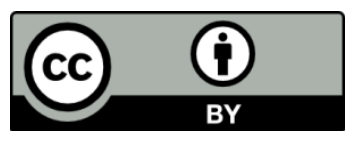

